\title{
Development of Iron- Crystalline Silica Ceramic Matrix Composites through Powder Metallurgy Technique
}

\author{
Sourav Debnath ${ }^{1}$, Akshay Kumar Pramanick ${ }^{2}$ \\ ${ }^{1,2}$ (Department Of Metallurgical and Material Engineering, Jadavpur University, Jadavpur, Kolkata-700032, \\ West Bengal, India )
}

\begin{abstract}
Ceramic matrix composites are widely demanded in all the sector of thermal, electrical and structural applications around the whole world. This present experiment aims to manufacture iron-crystalline silica ceramic matrix composites with average particle sizes around -150 micron. Crystalline silica matrix composites with 15, 20, $40 \mathrm{Wt}$. \% of iron were manufactured through conventional powder metallurgy techniques. The surface morphology of the composites were observed by optical microscopy (OM). Physical property like density, porosity and mechanical property like hardness were measured and reported.
\end{abstract}

Keywords: Iron- Crystalline silica, Ceramic matrix, Powder Metallurgy, Surface morphology, Density, Porosity, Hardness.

\section{Introduction}

With the development of modern industries, the requirement for new materials are increased significantly for various applications. In modern scenario, electrical/ electronic sectors are required ceramic based magnetic materials with limited current caring facility in addition of conventional materials. Iron is one of the well-known magnetic conductor materials available in the Earth. Available pure iron is not mechanically stable and it has also large weight, corrosion tendency. On the other hand, crystalline silica is one of the important member in ceramic family with light weight than iron, durable and can be used in the hearse environment.

In composite, one or more single phase material is added with one parent material for getting improved properties which give better performance, such as--- good strength at high temperatures, good structural rigidity, dimensional stability, light weight and low thermal expansion [1-6] than conventional single phase materials. In this study, we attempt to manufacture iron-crystalline silica ceramic matrix composite through conventional Powder Metallurgy technique as a substitute of ceramic based magnetic materials required in mainly modern electrical/ electronics industries.

\section{Experimental Procedure}

\subsection{Development of Iron- Crystalline Silica Ceramic Matrix Composite}

The matrix material used in the present study was crystalline silica $\left(\mathrm{SiO}_{2}\right)$ which was extracted from natural sand, described elsewhere [7-8] and commercially pure iron ( $\mathrm{Fe}$ ) powder $(99.7 \%)$ procured from MERCK, India. Then the mixture of iron- crystalline silica powder with composition 15\%, 20\% and $40 \%$ of iron (based on Wt. \%) were mixed in hand driven mortar parcel until very fine powder was produced, mesh size around $-150 \mu \mathrm{m}$. The compact powder was uniaxially hard-pressed using a steel mold having an internal diameter of $10 \mathrm{~mm}$ at a pressure of $450 \mathrm{MPa}$, with a 2-ton press, made by PEECO hydraulic pressing machine (PEECO Pvt Ltd, M/C NO.-3/PR-2/HP-1/07-08) for 4 min. Finally the samples were sintered in the muffle furnace (made by Nascor Technologies Private Limited, Howrah, West Bengal, India) at temperature $1150^{\circ} \mathrm{C}$ for 2 hours at a constant heating rate of $5^{\circ} \mathrm{C} / \mathrm{min}$ in nitrogen atmosphere. After heating, samples were cooled slowly in the same furnace.

\subsection{Testing and Characterization}

All the samples were polished sequentially via universal technic and then the weight and dimensions were taken for each sample before and after sintering. From the dimension measurement both green and sintered densities were calculated. 


\subsection{Microstructure}

\section{Results And Discursion}

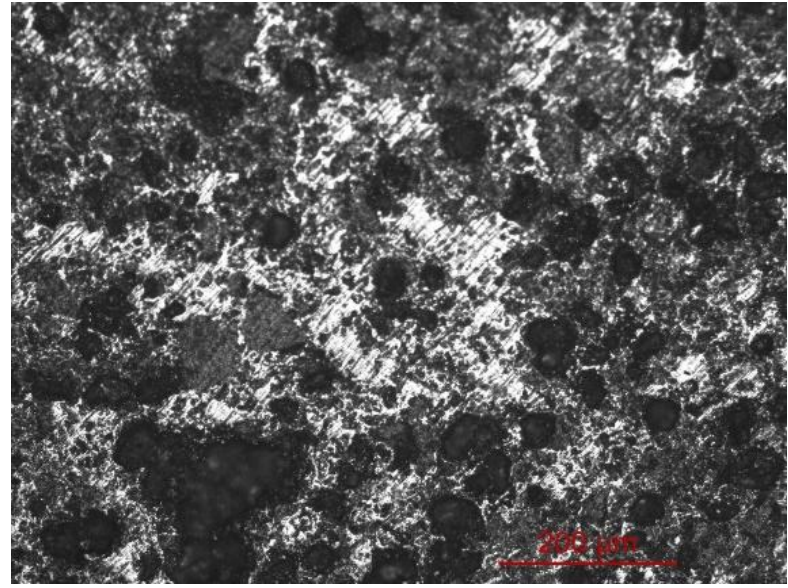

Figure 1: $10 \mathrm{Wt} \% \mathrm{Fe}-\mathrm{SiO}_{2}$ Composite at $100 \mathrm{X}$ magnification

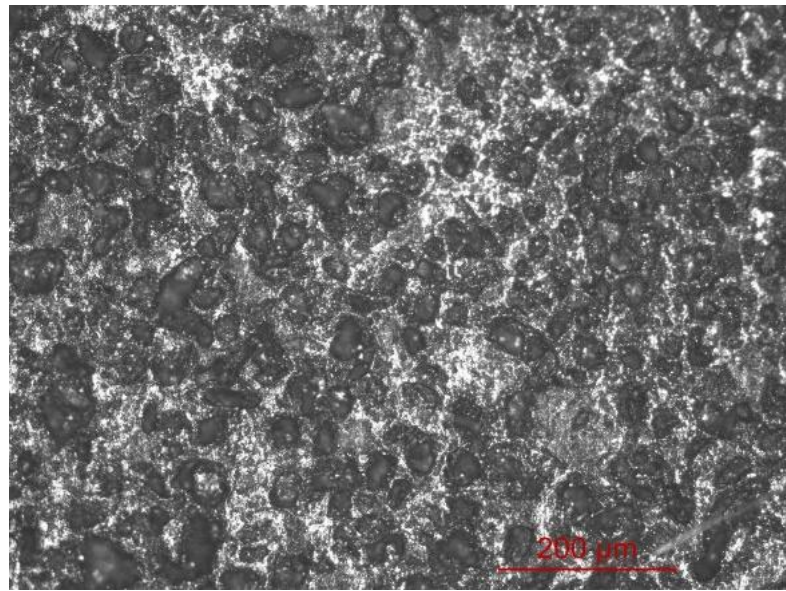

Figure 2: $20 \mathrm{Wt} \% \mathrm{Fe}-\mathrm{SiO}_{2}$ Composite at $100 \mathrm{X}$ magnification

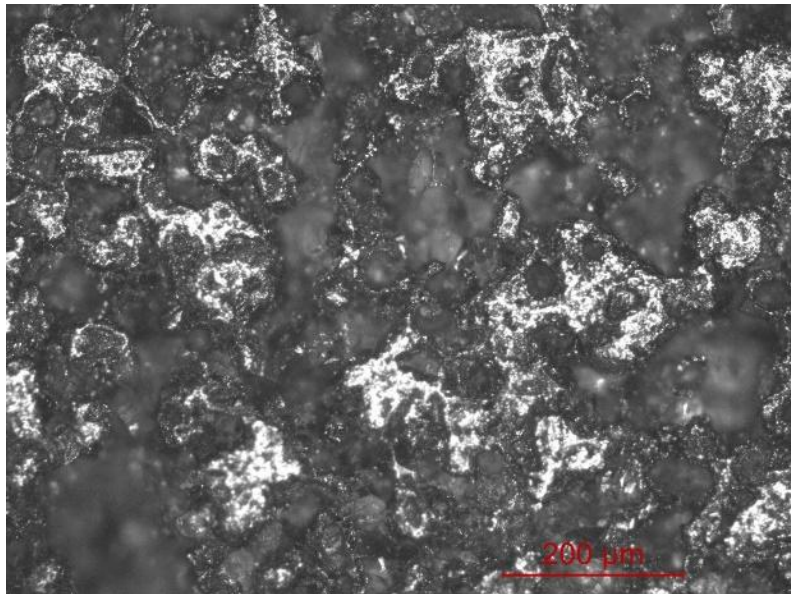

Figure 3: $40 \mathrm{Wt} \% \mathrm{Fe}-\mathrm{SiO}_{2}$ Composite at $100 \mathrm{X}$ magnification

Figure 1- 3 shows the microstructure of 15\%, $20 \%$ and $40 \%$ (based on Wt. \%) iron- crystalline silica composites respectively. In the figures (1 to 3 ), black portion indicates iron and white portion indicates silica. Iron is well distributed throughout the ceramic matrix. 


\subsection{Density Measurement}

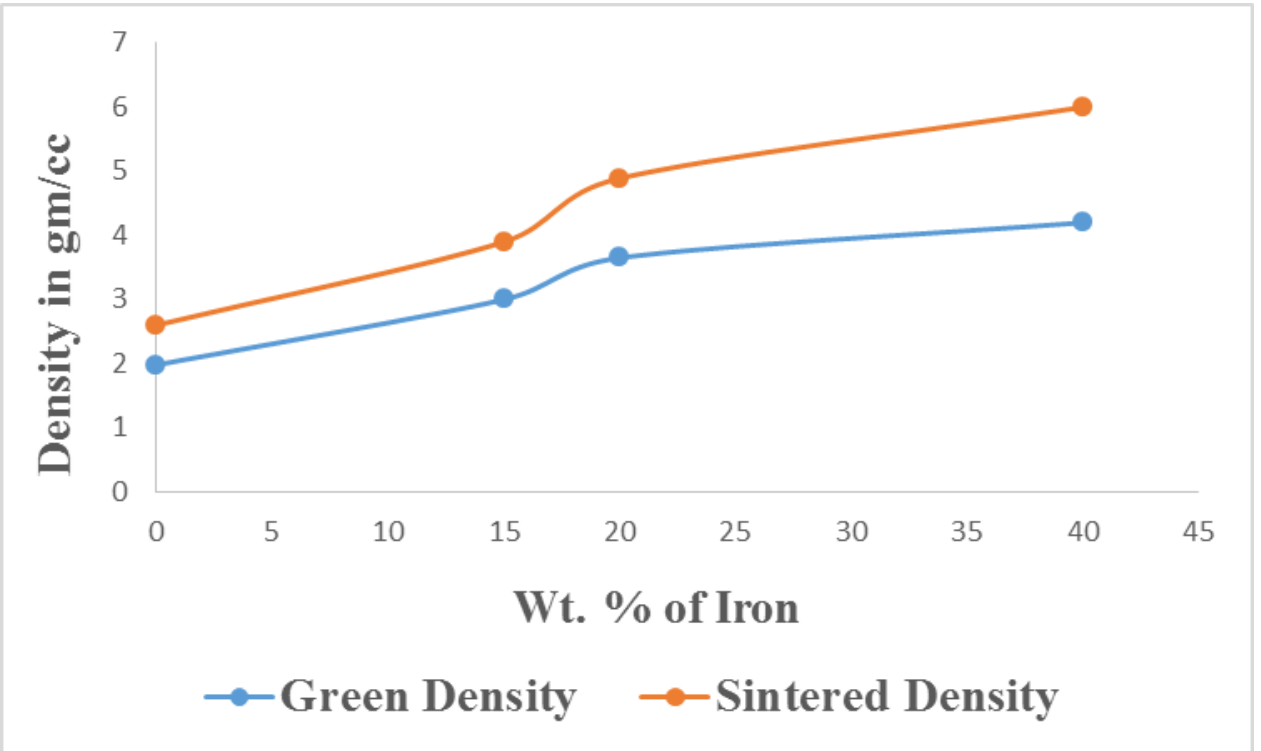

Figure 4: Density measurement

Figure 4 shows both green and sintered density of the samples. From figure, density is improved after sintering.

\subsection{Apparent Porosity}

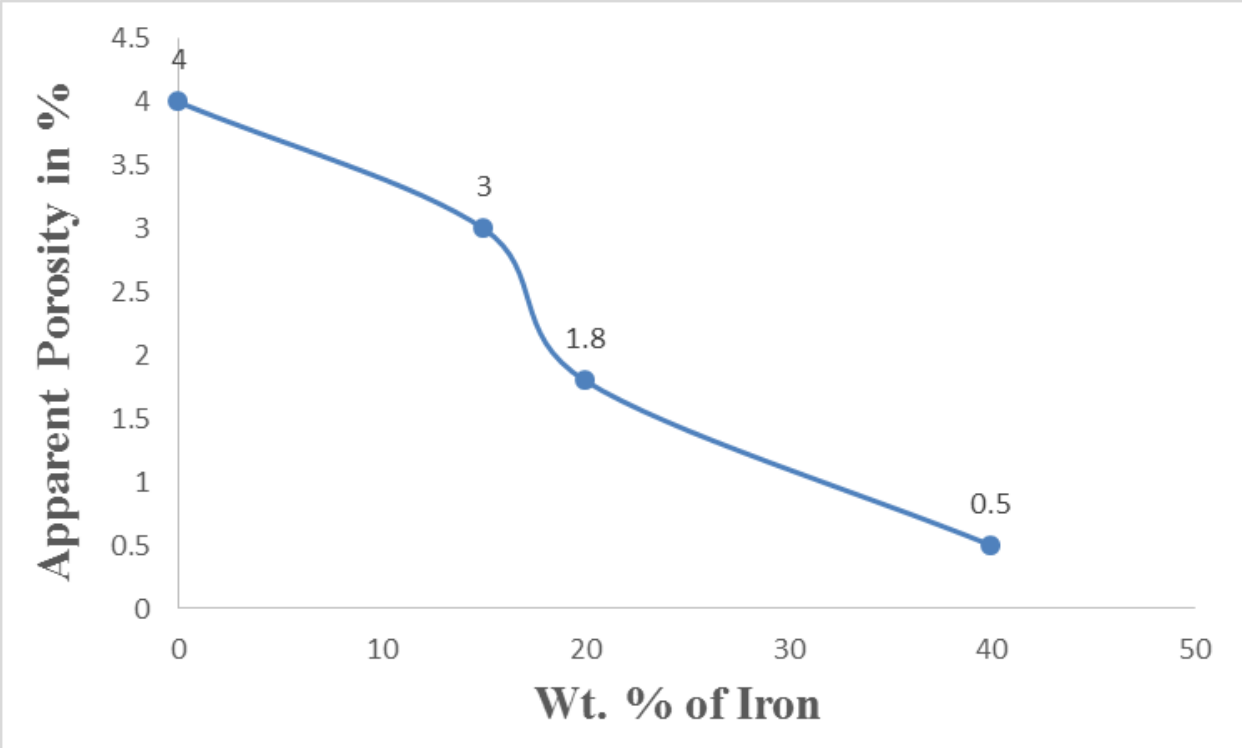

Figure 5: Apparent Porosity measurement

Figure 5 shows the apparent porosity of the developed composites. Apparent porosity decreases with increment of iron content into ceramic matrix.

\subsection{Hardness}

Table 1: Hardness Measurement

\begin{tabular}{|c|c|}
\hline Sample & RC Hardness \\
\hline $15 \% \mathrm{Fe}-\mathrm{SiO}_{2}$ & 22.8 \\
\hline $20 \% \mathrm{Fe}-\mathrm{SiO}_{2}$ & 27 \\
\hline $30 \% \mathrm{Fe}-\mathrm{SiO}_{2}$ & 50 \\
\hline
\end{tabular}

Table 1 suggests that hardness values were increased gradually with increment of iron into crystalline silica matrix. 


\section{Conclusion}

The significant conclusions of the studies based on iron- crystalline silica composites are as follows:

> Iron- Crystalline silica composites were developed successfully through powder metallurgy technique.

$>$ Morphology obtained from optical microscope was found to the uniform distribution of iron into crystalline silica.

$>$ The density, hence weight of iron-crystalline silica composites were increased with the increment of iron content.

$>$ The value of sintered density is much higher than green density, indicates the formation of bonding between matrix and second phase.

$>$ It is noted that mechanical property like RC hardness is improved significantly with increment of the iron content in the composite material. It is hoped that crystalline silica particle reinforced with iron were able to improve ductility than monophasic crystalline silica.

\section{References}

[1]. Sharma, S.C., Girish,B., Kamath, R., and Sathish, B.M., "Fractography, Fluidity and Tensile Properties of Aluminium/Hematile Particle Composite, Journal of Materials Engineering Performance," 8(3), 1999, pp- 309-314.

[2]. Sharma, S.C., Seah, K.H.W., Sathish B.M., and Ginish, B.M., "Effect of Short Glass Fibers on Mechanical Properties of Cast Al6061 Alloy Composites, Material Design," 17(5/6), 1996, pp- 245-250.

[3]. Sharma, S.C., "Albite Particles on the Co-efficient of Thermal Expansion Behavior of the Al6061 alloy Composites," Metallurgical \& Materials Transaction A 31, 2000, pp- 773-780.

[4]. Tjong, S.C., and Ma, Z.Y The High-Temperature Creep Behavior of Al Matrix Composites reinforced with SiC, A12O3 and TiB2 Particles, Composite Science Technology, 57(197), 697702.

[5]. Akbulut, H., Durman, M., and Yilmaz, F., "Higher Temperature Young's Modulus of Aluminium Short Fiber Reinforced Al-SiC MMCs Produced by Liquid Infiltration, Composite Science Technology," 14, 1998, pp- 299-305.

[6]. Seah K.H.W., Sharma, S.C., and Krishna, M., "Damping Behavior of Al 6061/Albite MMCs," Journal of ASTM International, 3(3) Paper ID 5A1 12394, March 2006

[7]. Sourav Debnath and Akshay Kumar Pramanick, "Development and Evaluation of Various Properties of Crystalline SilicaAluminium Metal Based Composites,” International Journal of Engineering Research and General Science, 4 (2), $2016,236-245$.

[8]. Sourav Debnath and Akshay Kumar Pramanick, "DEVELOPMENT AND STUDY ON DIFFERENT PROPERTIES OF ALUMINIUM- CRYSTALLINE SILICA CERAMIC MATRIX COMPOSITES AT DIFFERENT SINTERING TEMPERATURES," IJERGS, 4 (3), 2016, 415- 423.

[9]. Sourav Debnath, Sourav Basu, Akshay Kumar Pramanick, "Development and Study on Various Properties of Titanium Oxide -Tri Calcium Phosphate Composites through Powder Metallurgy Technique,” IOSR-JMCE, e-ISSN: 2278-1684,p-ISSN: 2320-334X, Special Issue 2K16, 2016, PP 01-06.

[10]. Sourav Debnath, Sujan Krishna Samanta, Akshay Kumar Pramanick, "Preparation and Study on Nickel Coated Aluminium through Electroless Deposition Technique," IOSR-JMCE, e-ISSN: 2278-1684,p-ISSN: 2320-334X, Volume 13, Issue 3 Ver. IV (May-Jun. 2016), pp- 73-77. 